\title{
Community Led Practices and Cultural Planning: Methodological Approaches and Practices for Sustainable Urban Development.
}

\author{
Nicola Boccella ${ }^{1, a}$, Giuseppina Cassalia ${ }^{2, b}$ and Irene Salerno ${ }^{3, c}$ \\ ${ }^{1}$ Via Nomentana, 261, Rome, Italy \\ ${ }^{2}$ Mediterranea University of Reggio Calabria - PAU - Department of Heritage, Architecture, Urban \\ Planning, Via Salita Melissari - 89124, Reggio di Calabria, Italy \\ ${ }^{3}$ Via Vincenzo Petra, 9, Rome, Italy \\ anicola.boccella@gmail.com, bgiuseppina.cassalia@unirc.it, ${ }^{c}$ irene.salerno@uniroma1.it
}

Keywords: Urban Sustainable Development, Cultural Planning, Community Involvement Practices.

\begin{abstract}
The purpose of this paper is to define a common framework of the Cultural Planning application, in order to provide a range of theoretical and practical tools to combine the conservation of cultural heritage and local development in urban and rural areas, where the management of cultural heritage can have a significant role improving the active participation of the community in the public decision making process.

The idea of participation is, at different levels and in different contexts, strongly present in Europe; modern urban design and planning projects are increasingly including local communities in urban development planning activities. In conclusion, the paper argues the possibility of applying the Cultural Planning tool in the field of the Metropolitan City of Reggio Calabria strategic planning.
\end{abstract}

\section{Introduction}

The economic, social, cultural and demographic developments, over the last decades, have been characterized by large regional transformations that have seen the city of the third millennium engaged in a constant and continuous rethinking of their areas [1].

In Europe, and more recently in Italy reuse, redevelopment, new functions, retrain become one of the major objectives of the government and the private sector. Europe has a long history of urbanization and most of its economy is concentrated in cities. Despite that, standardised data on European cities are not easily available and only recently the European Commission has released data on metropolitan NUTS-3 regions that allow carrying out empirical analysis on the characteristics and determinants of urban agglomerates in Europe [2].

The changes that have characterized metropolitan regions have inspired research on agglomeration economies and regional planning, especially with reference to the concepts of urban regions, edgeless cities and mega city regions [3].

On the other hand, the process of growth that has characterized the Italian planning system over the last century and a half, have considerably affected the shape and structure of urban-rural regions, both in terms of their physical, social and cultural dimension.

The complexity of the choice that governmental agencies are facing to, requires an ability to implement complex decision making processes, flexibility and innovation in order to ensure a longterm planning, an integrated resource for promoting participation, access to the arts and culture and social integration.

This paper treats the so-called cultural planning approach as a way of enabling policy-makers to think strategically about "culture" as economic resource for urban development. Furthermore it draws a picture of the most popular and relevant community led approaches currently available in Europe, finally proposing an hypothesis of integration and application of such methods to the context of Metropolitan City of Reggio Calabria. 


\section{Urban development participatory approaches in Europe}

In the last year, starting from the first experimentations with the famous "Planning for real" method, born the "70s in the United Kingdom, a variety of techniques focused on the concept of planning with communities have been developed. Such idea is at the basis of community led practices, the most interesting of which are described in this paper. Concerning the participatory planning, in Europe are currently available the following methods [4]:

EASW (European Awareness Scenario Workshop). This method was born in Denmark with the purpose of reaching agreement between the diverse interested parties (stakeholders) inside a local area or for consensual agreement on a larger scale. On a practical level, the EASW consists of a workshop, which lasts about two days, with the participation of thirty participants divided into four main categories of actors: politicians/administrators, traders, technicians/experts, users/citizens. The workshop is managed by a team of facilitators, involves two basic steps: the development of future visions and the development of ideas. In the first phase, each of the four categories of actors are invited to develop two hypothetical future scenarios, respectively oriented to a "catastrophic vision" that may pose more dangerous risks, and an "idyllic vision" able to identify a large number of ambitious objectives. A plenary discussion stage allows comparing the scenarios proposed by the various categories and identifying the four most important issues on which to focus the work during the second phase.

With regard to future sessions of brainstorming techniques and negotiation, each group has a large number of ideas and possible methods of implementation, including a maximum of five to be presented at the closing plenary session of the workshop. The maximum number of the ideas presented is therefore equal to 20. During the closing plenary session, after the presentation of each idea a final vote from all participants will point out the five most significant ideas to be implemented through joint action plans.

Future Search. The Future Search approach is focused on a 2 or 3 days conference with the technique of visioning at its core. The conference explores the past, present and future of a community, with the aim of producing a strategic plan. Key element of this approach is to establish some common ground on which participants can build and then develop a plan. The emphasis is on self-managed discussion and taking personal responsibility for implementation of actions.

The ideal number of participants is 64 allowing for eight groups of eight people in each discussion group.

Planning for Real. This method was born in the UK in the 70s; since that time, it has been widely exploited in numerous countries, both European and non-European.

At the centre of it there is the construction of a model of the area in question. Where possible, the model should be made by local people to build a sense of ownership and to ensure engagement from the outset. Cards with ideas or proposals are made available. People can select or write their own cards which reflect their interests and place them on the model where they think the idea should be implemented. Planners, designers and officials can answer questions but only if asked. During the event a picture emerges of the changes the participants would like to see.

The cards are counted and their locations on the model noted. These details are then fed back to people, discussed further and prioritised at public meetings or small group discussions. After prioritisation, additional technical information (on feasibility, cost, policies etc.) can be provided and used to develop an action plan.

Interactive planning. This method has been developed in Italy by professors Alessandro Giangrande and Elena Mortola, and is inspired by the theories of Christopher Alexander. It deals with a forum and it exploits the ICT for consultation purposes.

After reviewing the preliminary program design and the documentation already collected, members of the working group together with residents make a thorough inspection to identify the 
scope and represent on a map all the elements of "wholeness" - which is the deep structure that characterises every place, and helps to make it "living".

The next activity consists of the construction of the future, dynamic visioning scenario, which anticipates the changes that the relevant territorial actors want in their living spaces. This does not refer to a specific time horizon, but is a "vision" generally oriented in a distant future that can always be updated in the light of the environment changed situation.

The final phase of the process consists in the unfolding process, meant as a process that transforms a context while preserving the deep original structure. In practice, in developing the project, the working group will take into account both elements represented on the map of wholeness and the proposed future scenario.

The working group publish and regularly update the blog the partial results of the design process. The members of the Forum and all other citizens can at any time access the blog to post their comments, so this strategy is highly interactive.

\section{Paradigm shift approaching culture: its role in local sustainable development}

The regional-economic thought became aware of the importance of cultural heritage as a social resource that improves the quality life of the community, and further evolves into the season of the knowledge economy, where the historic heritage and tacit knowledge gained locally raising them explicitly to the production factors of strategic significance for local development and global networking [5].

'Culture' has been increasingly seen as an important resource for the achievement of a wide variety of policy goals. The extent to which such an amorphous subject as 'culture' is actually capable of delivering the benefits that other policy fields are concerned with is currently, however, open to question. Research that has investigated the contribution of culture to the attainment of specific policy goals has been undertaken for some years and given results [6].

Clearly, there are significant difficulties involved in trying to use 'culture' as a basis for public policies. Attempts to resolve these problems do exist, involving a range of strategies from the development of new assessment criteria for the evaluation of the impact of cultural policies, to new approaches to integrating culture into the activities of governments and organisations [7,8]. In respect to the latter of these changes, the development of cultural planning approaches has been promoted to offer the possibility of not only producing a meaningful set of specific policies oriented at various understandings of 'culture', but also providing an over-arching framework within which democratic governments can effectively and efficiently serve their community [8].

Strategies for urban and rural development have evolved over the past decade as a tool to face new challenges. Relating to the local development ground, the cultural dimension becomes a possible field of implementation for profitable and innovative governance. The idea of cultural planning is based on the strategic value recognition of local cultural resources. Adopting this point of view, it also affects the innovative way of conceiving the cultural resource itself. Apart from an interest in the specific cultural aspects, cultural planning considers them as part of the vision on urban strategies. The basic premise behind the cultural planning approach consists of wide-ranging methodology adopted to community development matters, and in a holistic view based on a cultural resources integrated management [9]. These resources are seen to consist of a range of activities, structures and identifying characteristics (such as common rituals; local dialects; the quality of the built environment; specifically local products) and should, it is argued by proponents of cultural planning, be used to apprise the management and development of local areas [10]. Lia Ghilardi identifies two main types of action to achieve an effective cultural planning [11]: a) Mapping: in this phase it is necessary to conduct an exploration or mapping of the distinctive place activity to maximize opportunities to better respond to community needs; b) Strategy Building: the potential resources, investigated through the first stage, must be placed within an operational framework in which they become the core of the planned actions. This stage is useful to create links between the different interest groups; more collaboration means more ideas, more resources and even greater constructive energy. 
The development of cultural planning approaches from the Eighties onwards has taken place to the greatest extent in the USA, although it is now beginning to be utilised in continental Europe with increasing frequency as well. It is a way to make it possible for policy makers, the use of local hallmarks resources, in order to achieve economic and political sustainability, while intercepting and satisfying local community needs and aspirations. It should be specified, that cultural planning is not meant to plan culture. Cultural planning is a culturally sensitive approach to urban planning and public policy. Criticism of some aspects of the approach have also been developed, concentrating on a perception that incorporates modified public policy aims and an unhelpful definition of 'culture' [12]. The latter of these criticisms is potentially the more damaging of the two as it implies that, firstly, there is a better definition of the key term for this policy sector, and secondly that the success of the policy in this area depends upon an adequate definition of the term. Therefore, culture is considered as a way of life, which merges heritage with other aspects of the local culture in everyday life. Cultural heritage becomes one of the points of view of a larger design, which helps local governments to identify the distinctive cultural resources of a place, and can be used to foster community development, as well as its economy. Unfortunately, questions as how and why it is worthwhile to preserve, enhance and integrate culture(s) have not still an explanation.

The following paragraph contributes to the current discussion, arguing a potential application of the cultural planning approach to the strategic planning of the Metropolitan City of Reggio Calabria.

\section{Concluding hypothesis of an integrated methodology applicable to the Metropolitan City of Reggio Calabria}

Designing the urban- regions, means to represent all the coexisting diversities, producing a series of local changes that respond to the more general global changes and developing a new language that allows to bring out and enhance regional value. To achieve cultural planning, embraced the economic, political and social fields, the development of an integrated and participated cultural plan is needed. The idea of participation is, at different levels and in different contexts, strongly present in Europe; modern urban design and planning projects are increasingly including local communities in urban development planning activities. Aiming at re-designing a place (a rural region such as a metropolitan city), as close as possible to its authentic identity - and open to diversity - whether it is expressed in the quality or quantity of the offer, it should be evaluated as a systemic whole, sketched out by its multi-dimensional layers. In recent years the importance and richness of local systems, especially in underdeveloped areas - such as Calabria, Southern Italy - has been recognized, both in academic and administrative sector $[13,14]$. The awareness of local resources, that means to analyse and interpret regional vocations, is particularly significant as a driving force for the development of disadvantaged areas. The recognition of regions as multifaceted products is evident from the analysis of the EU, National and Regional policies. The European Community, in particular, has largely reoriented its regional policy objectives to encourage and support local economies, especially those with structural disadvantages [13]. The decentralization has been implemented in the twenty-first century, namely the transfer of authority and responsibility for public functions from the central government to civil society, strengthening the position of local governments expanding their influence from the local level back to the national level. This trend brings with it some new features to the local government who must find new ways to organize and interpret the regions they represent, embracing all layers of regional organization. According to the Italian Bill 1212, the metropolitan city of Reggio Calabria will be established on 1 January 2016. It will propose this local organization, with city council's decision, and it will be adopted at the procedure laid down in Article 6, paragraph 4, of the merged legal text [15]. In addition, the statute provides for the homogenous areas formation, taking account of regional specificities, a coordination body, connected to the metropolitan city bodies, with no new or increased costs for public finance. This model definitely requires the overcoming of polycentric administrative functions, characterized, for example, by local planning activities, and the coordination of most of the administrative activities. 
The model of a metropolitan city, has not to be seen as an added value to the system of the municipalities included in the area, but better as an institutional pilot for new ways of organization of services and managing resources.

To support this articulated and complex regional management, a strategic plan is needed, that is able to valorize the metropolitan area features like a conurbation characterized by economic, social, cultural and institutional links. Particularly, the paper proposes to integrate the cultural planning method to the forthcoming strategic plan for the Metropolitan City of Reggio Calabria, in order to:

- Create a new operational tool for the implementation of the Strategic Plan, which translates into concrete actions on field, of what has been theorized in the first phase, or rather using cultural resources and activities to apprise the management and development of the forthcoming metropolitan city.

- Extend the strategic interventions to the municipality's boundaries, strategically planning the development of Reggio Calabria and its system of regional interconnections, working to enhance the distinctiveness of each area. The primary goal, for Reggio Calabria, is to manage such a central role both within the area of the Strait, and the regional system, through the infrastructure and services adaptation, the equipment networking and intangible assets integration (such as systems accessibility: ports, airports, rail and road network, computer networks, systems, culture, tourism, local welfare, health, energy, etc.).

- Support community participation, involving the regional population with the goal of sustaining their ever more active participation in projects, plans and programmes drafting of metropolitan transformations [16].

In conclusion, the integration of participatory planning strategies to a cultural planning approach can be profitably applied to small and medium scale contexts, as the cases of the Metropolitan City of Reggio Calabria. It opens new perspectives for research on the role of cultural planning within a regional strategy, highlighting how, in the case of Reggio Calabria and its region, the cultural heritage must be conceived as a complex network of relationships established among local communities and places, made of values, customs, traditions and contaminations. This approach aims not to isolate and freeze cultural resources, but to valorise them into a network of relationships with other resources. The scope of the application of this method is to, finally, drive considering culture as a real way of life, that is, as a set of values involving the daily community behaviour, giving meaning to human actions.

\section{References}

[1] I. Sagan, H. Halkier: Regionalism Contested. Institution, Society and Governance. Ashgate, Aldershot (2005), pp. 163-176

[2] Dijkstra, L, H. Poelman: Metropolitan regions in the EU, European Union Regional Policy, Regional Focus n.1/2011.

[3] L. Gagliardi, M. Percoco: Understanding European urban development: A review of selected issues, Università Bocconi, Milano (2012)

[4] A. Caperna, A. Giangrande, P. Mirabelli, E. Mortola: Partecipazione e ICT, Gangemi Editore, Roma (2013)

[5] G. Cassalia, C. Ventura: Festivals, tourism and rural development: A key for cultural heritage preservation, in: Active Countryside Tourism Conference proceedings, ICRETH and RSA, Leeds (2013)

[6] C. Dümcke, M. Gnedovsky: The Social and Economic Value of Cultural Heritage: literature review, EENC Paper (2013) 
[7] F. Calabrò, L. Della Spina: The cultural and environmental resources for sustainable development of rural areas in economically disadvantaged contexts. Economic-appraisals issues of a model of management for the valorisation of public assets, in: 3rd International Conference on Energy, Environment and Sustainable Development (ICEESD 2013), Advanced Materials Research Vols. 869-870 (2014), pp 43-48

[8] A. Everitt: The governance of culture: approaches to integrated cultural planning and policies Council of Europe Pub., Strasbourg (1999).

[9] C. Gray: Joining Up or Tagging On?: The Arts, Cultural Planning and the View From Below, in: Public Policy and Administration, Vol. 19, No. 2 (2004), pp. 38-49

[10] F. Bianchini, M. Parkinson: Cultural Policy and Urban Regeneration: The West European Experience, Manchester University Press, Manchester (1993).

[11] L. Ghilardi: Culture at the Centre, National Cultural Planning Steering Group, Glasgow (2005).

[12] R. Lloyd, T. Nichols Clark: The city as an entertainment machine, in: Critical perspectives on urban redevelopment, Research in urban sociology, edited by Kevin Fox Gotham, Vol. 6, JAI Press/Elsevier, Oxford (2001), pp. 357-78

[13] Commission of the European Communities, Fifth Report on Economic, Social and Territorial Cohesion. Investing in Europe's future, November 2010.

[14] A. Magnaghi: Il progetto locale, Bollati Boringhieri, Torino (2000).

[15] Italian Bill dated December 21, 2013 n. 1212.

[16] G. Cassalia: Il Festival, la comunità locale e il turismo culturale, in: LaborEst, pagine di estimo e valutazione di piani, programmi e progetti, Laruffa editore, Reggio Calabria, 4/2009 (2009), pp. 57-61 